\title{
A study on survivors of acute myocardial infarction developing transient ischemia on Holter monitoring
}

\author{
Jalali $\mathbf{T}^{\mathbf{1}}$, Goyal $\mathbf{V}^{\mathbf{2}}$ \\ ${ }^{1}$ Dr Tariq jalali, Associate Professor, Department of Medicine, Chirayu Medical College and Hospital, Bhopal. ${ }^{2}$ Dr Vikas \\ Goyal, Assistant Professor, Department of Medicine, Chirayu Medical College and Hospital, Bhopal, MP, India
}

Address for correspondence: Dr Tariq Jalali, Email: roshanchanchlani@gmail.com

\begin{abstract}
Introduction: Increasing array of medical intervention available to modify the likelihood of developing recurrent episode of myocardial ischemia, it is important to identify patients of risk of provocable myocardial ischemia before discharge. Material Methods: longitudinal study carried out in a tertiary care hospital of central India, over a period of one year. During the monitoring period, the patient was once subjected for 100-meter brisk walk. Result: Out of 64 cases, $6(9.5 \%)$ cases developed ischemia during Holter, in male it was 5(10.2\%) while in female it was $1(6.67 \%)$. 6.3\% of total cases suffered from sustained VT during hospitalization. $42.5 \%$ of cases of anterior wall myocardial infarction were presented with sinus tachycardia, it was found to be statistically significant $\left(x^{2}=73.55, \mathrm{p}<0.001\right)$. Conclusion: After acute myocardial infarction, pre-discharge Holter monitoring (including brisk walk) is a good non-invasive method to detect ischemia in high risk patients.
\end{abstract}

Keywords: Holter Monitoring, Myocardial Infarction, Tobacco

\section{Introduction}

Acute myocardial infarction (MI) continues to be a major health problem. Although the death rate has declined from $30 \%$ to $7.5 \%$, in present era it is still fatal event in approximately one third of the patients [1]. Because acute myocardial infarction strikes an individual during the most productive years, it can have profound delirious psychological and economic ramification. The most important determinant of prognosis after acute myocardial infarction are left ventricular function, occurrence of ventricular arrhythmias, extent of coronary artery disease and myocardial ischemia $[2,3,4]$. Given the increasing array of pharmacological intervention catheterization and surgical operation available to modify the likelihood of developing recurrent episode of myocardial ischemia, it is important to identify patients of risk of provocable myocardial ischemia before discharge. A pre-discharge evaluation for ischemia allows clinician to select patients who might benefit from catheterization and revascularization after acute myocardial infarction and to assess the adequacy of medical therapy for those

Manuscript received: $20^{\text {th }}$ Sept 2015

Reviewed: $1^{\text {st }}$ Oct 2015

Author Corrected: $7^{\text {th }}$ Oct 2015

Accepted for Publication: $20^{\text {th }}$ Oct 2015 patients who are more suitable for conservative management. During the last few decades, for the detection of myocardial ischemia, many non-invasive methods have been used like stress thallium-201 scintigraphy, stress echocardiography, exercise electrocardiography, ambulatory electrocardiography etc, but the principal method of finding the post myocardial infarction ischemia related is exercise stress test [5]. Ambulatory ST-T segment monitoring is a reliable means of detecting myocardial ischemia during daily life in patients with coronary artery disease [6]. The episode of silent myocardial ischemia typically outnumbers the episode accompanying angina [7]. 81\% to $100 \%$ of the ischemic episodes recorded by Holter monitoring are asymptomatic [8] and when compared to exercise testing, the additional prognostic information of Holter monitoring is limited [5]. In patients who are able to do pre-discharge exercise stress test, ambulatory monitoring is considered less sensitive in detecting patients with ST segment depression [8]. These results suggest that the ambulatory ST segment monitoring should not be used as a routine screening test for continuous ischemia in early post infarction period. In the present study, we had tried to increase the sensitivity of ambulatory ECG monitoring for ischemia 
episode by introducing a 100- meter brisk walk during Holter monitoring. Finally, the aim of the study was to determine that with addition of 100 meter brisk walk, whether pre-discharge Holter monitoring can be taken for pre-discharge sub-maximal exercise stress test for the detection of ischemia after acute myocardial infarction in patients who are not fit for stress test, to determine the baseline characteristics of survivors of acute myocardial infarction and its correlation with transient ischemia on holter recording.

\section{Material and Methods}

The present longitudinal study was carried out in the medicine department in a tertiary care hospital of central India, during the period of July 2002 to October 2003. After the ethical committee approval all the cases during the study period fulfilling the inclusion and exclusion criteria were included in the study. The inclusion criteria was, those who had acute myocardial infarction suggested by 12 lead ECG were included in the study. Electrocardiographic diagnosis for acute myocardial infarction was made as when:- ST elevation more than $2 \mathrm{~mm}$, or abnormal $\mathrm{Q}$ wave $>2 \mathrm{~mm}>25 \%$ of $\mathrm{R}$ wave in same lead, or QS complex. Right ventricular infarction was diagnosed when:- ST elevation in $\mathrm{V} 1(>1 \mathrm{~mm}) \mathrm{V}_{4} \mathrm{R}-\mathrm{V}_{6} \mathrm{R}$ or $\mathrm{ST}$ depression in $\mathrm{V}_{2<50 \%}$ of ST elevation in a aVF or ECG evidence of inferior wall or inferior posterior wall infarction. Electrocardiographic evidence of sub endocardial infarction were - ST depression and deep inverted T wave in mild precordial leads (symmetrically) lead I and II. Exclusion criteria were- patient that were unable to ambulate - cerebrovascular accident, cardiac failure (NYHA-IV) on the day of test or those denying a written consent for Holter monitoring or patient presenting with Left Bundle Branch Block(LBBB). After confirmation of diagnosis of acute myocardial infarction these patients were treated by Nitroglycerin, Aspirin, Heparin, clopidrogel along with conventional symptomatic drugs for pain relief etc. Thrombolytic therapy was given in appropriate cases. Before the patient were discharged all the patients were subject to 24 hours Holter monitoring after the written informed consent. The Digi track plus Holter monitoring was used; it was a battery operated solid state recorder for 24 to 48 hours of continuous recording for ambulatory patients. It was a 3 channel frequency modulated, with frequency response of 0.05 hertz to 60 hertz. Patient was given a diary in which he/she had to maintain full record of his/her symptoms, activity and time during the monitoring period. Event signal button was explained to the patient. During the monitoring period, the patient was once subjected for 100-meter brisk walk. Patient was asked to walk to his/her maximum speed and try to complete 100 meter as early as he/her could (1 to 3 minute). Patients were instructed to give up the walk if any symptoms like chest pain, palpitation, perspiration and 'ghabrahat' arose. After the walk patient's vitals were examined and were kept under observation for at least one hour or more as required. All the Holter equipment performed in accordance with the American Heart Association specification with respect to the rate and frequency response necessary to record ST segment alteration reliability. The ZymedHolterScaner for window 1810 scans a 24 hours ambulatory ECG; detect arrhythmia and ST segment changes and heart rate variability. Report include the cover page, documented electrocardiographic strips, supraventricular and ventricular arrhythmia summary, ST changes summary, heart rate variability and QRS morphology description is prepared which was then scanned manually and final reporting was done.

The collected data were entered and analyzed using Microsoft office window excel 2007 and SPSS version 16 (SPSS 16.0 for Windows, release 16.0.0. Chicago: SPSS Inc). Frequencies of all variables were taken to check frequencies. To show the association or difference for categorical data chi square test was applied. We considered the association or difference to be significant when the $\mathrm{p}$ value was less than 0.05 .

\section{Result}

The study comprised of 64 cases of acute myocardial infarction brought to intensive coronary care unit. Maximum number of patients were observed in the age range 56-65 years comprising $42.1 \%$ (27 cases) of the total Fig.1 . There were $49(76.5 \%)$ males and $15(23.5 \%)$ females. These patients underwent 24 hours Holter monitoring $8 \pm 3$ days after acute myocardial infarction. In the present study out of total 64 cases, there were $40(62.5 \%)$ cases of Anterior wall MI (AWMI), $16(25 \%)$ cases of Inferior wall MI and 8 (12.5\%) cases of combined MI, with more or less equal distribution among male and females. 4(10\%) cases of AWMI developed ischemia, 1(6.25\%) cases of IWMI and one (12.5\%) case of combined (anterior + inferior) MI developed ischemia. Out of 64 cases, $6(9.5 \%)$ cases developed ischemia during Holter, in male it was $5(10.2 \%)$ while in female it was $1(6.67 \%) .50 \%$ cases whose blood pressure on admission was less 
than $90 \mathrm{~mm} \mathrm{Hg}$ ST segment changes during Holter monitoring and this was found to be $\operatorname{significant}\left(x^{2}=102.7, \mathrm{p}<0.001\right)$. 40 out of 64 cases $(62.5 \%)$ were having minimum heart rate between 41 to $60 \mathrm{bpm}$ and 1 case (16.7\%) whose heart rate was <40 bpm during holter monitoring developed Ischaemia. 33 out of 64 cases $(51.6 \%)$ had maximum heart rate between 101-120 bpm during Holter. 8.7\% cases with supraventricular premature complex developed ST segment depression during Holter monitoring $\left(x^{2}=35.55, \mathrm{p}<0.001\right) .33 .3 \%$ cases with ventricular premature complex more than or equal to $10 \mathrm{bpm}$ and 2 out of 12 cases (16.7\%) with atrial runs developed ST segment depression during Holter monitoring $\left(x^{2}=10.55, \mathrm{p}<0.001\right) .45 .3 \%$ cases achieved $65 \%$ to $74 \%$ of THR during Holter monitoring which was found to be highly significant. 21 cases $(32.8 \%)$ out of 64 cases were able to attain more than equal to $75 \%$ target heart rate.

Fig.1 Age and gender wise distribution of cases

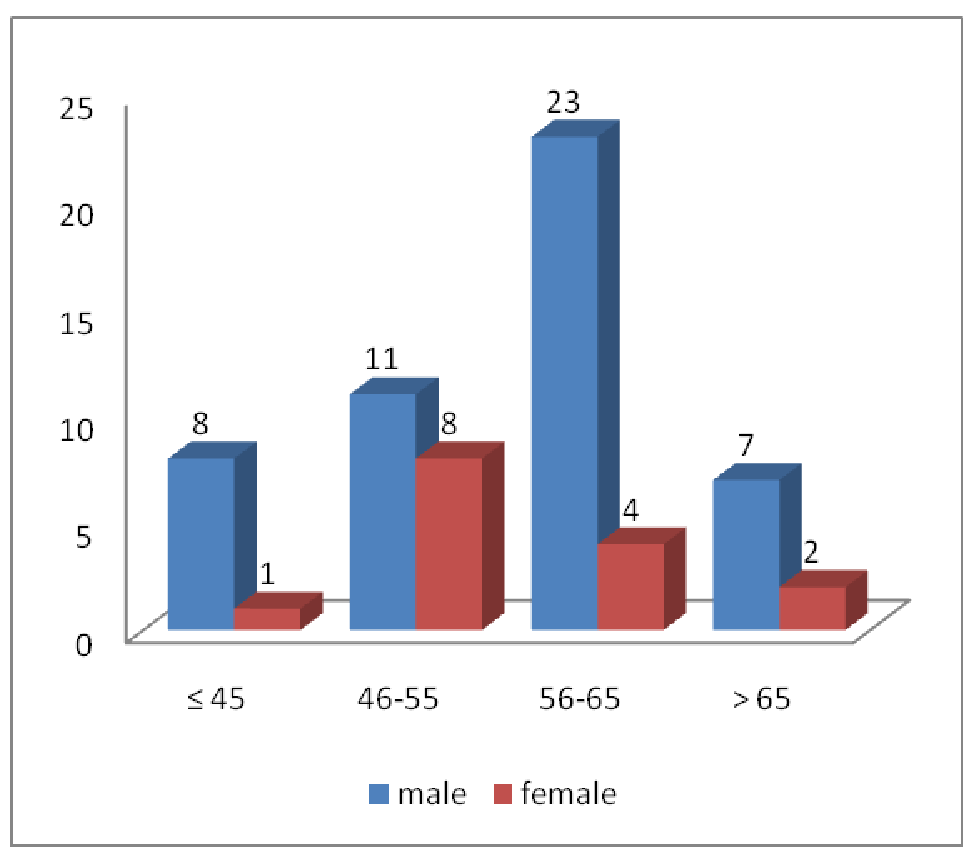

Table No 1: Association of type of myocardial infarction with ischemia recoded during Holter monitoring

\begin{tabular}{|l|c|c|c|}
\hline \multirow{2}{*}{ Type of MI } & \multirow{2}{*}{ Total(n=64) } & \multicolumn{2}{c|}{ Ischemia during Holter monitoring } \\
\cline { 3 - 4 } & & No. & \% \\
\hline AWMI & 40 & 4 & 10 \\
\hline IWMI & 16 & 1 & 6.25 \\
\hline combined (AWMI + IWMI) & 8 & 1 & 12.5 \\
\hline Total & 64 & 6 & 9.4 \\
\hline
\end{tabular}

Table No. 1 shows AWMI had significant number of cases 4(66.7\%) developed ischemia on holter $\left(x^{2}=17.55, \mathrm{p}<0.001\right)$. $33.3 \%$ of cases who had CCF during hospitalization developed ST segment change during holter monitoring $\left(x^{2}=35.9\right.$, $\mathrm{p}<0.001)$

Table No: 2 Distribution of cases according to complication during hospitalization and their relationship with ischemia during Holter monitoring.

\begin{tabular}{|l|c|c|c|c|}
\hline \multirow{2}{*}{$\begin{array}{c}\text { Complication during } \\
\text { hospitalization }\end{array}$} & \multicolumn{2}{|c|}{ Total(n=64) } & \multicolumn{2}{c|}{$\begin{array}{c}\text { Ischaemia detected Holter } \\
\text { monitoring }\end{array}$} \\
\cline { 2 - 5 } & No. & \% & No. & \% \\
\hline LVF & 24 & 37.5 & 4 & 16.7 \\
\hline CCF & 3 & 4.7 & 1 & 33.3 \\
\hline Cardiogenic shock & 2 & 3.1 & 0 & 0 \\
\hline Pericarditis & 2 & 3.1 & 0 & 0 \\
\hline
\end{tabular}


$6.3 \%$ of total cases suffered from sustained VT during hospitalization.42.5\% of cases of anterior wall myocardial infarction were presented with sinus tachycardia, it was found to be statistically $\operatorname{significant}\left(x^{2}=73.55, \mathrm{p}<0.001\right)$

Table No: 3 Distribution of cases according to Arrhythmia during hospitalization and ST change during Holter monitoring.

\begin{tabular}{|l|l|l|l|l|}
\hline \multirow{2}{*}{ Arrhythmia during Hospitalization } & \multicolumn{2}{|l|}{ Total(n=64) } & \multicolumn{2}{l|}{$\begin{array}{l}\text { Ischaemia detected Holter } \\
\text { monitoring }\end{array}$} \\
\cline { 2 - 5 } & No. & $\%$ & No. & $\%$ \\
\hline Ventricular tachycardia & 4 & 6.3 & 1 & 25 \\
\hline PSVT & 1 & 1.6 & 0 & 0 \\
\hline Atrial fibrillation & 1 & 1.6 & 1 & 100 \\
\hline isorhythmic Dissociation & 1 & 1.6 & 1 & 100 \\
\hline
\end{tabular}

$14.28 \%$ of cases whose heart rate at admission was more than equal to $100 \mathrm{bpm}$ developed ST segment depression in Holter monitoring $\left(x^{2}=13.4, \mathrm{p}<0.001\right)$.

\section{Discussion}

Ischemia following acute myocardial infarction is a known phenomenon. It may be symptomatic or asymptomatic. With the technical development in ambulatory ECG (Holter), for the measurement of ST segment alteration it is possible to detect episodes of ischemia more accurately. It is well known fact that excersice stress ECG, thallium scintigraphy, radionuclide ventriculography or echocardiography are methods for detecting ischemia in post infarction patients. Present study consisted of 64 cases of acute myocardial infarction admitted in medicine department of tertiary care institute of central India. Out of 64 cases, ischemia was recorded in 6 cases $(9.4 \%)$. Out of these 6 cases, 4 cases were of AWMI (66.6\%) and 1 (16.7\%) each of IWMI and combined MI (AWMI + IWMI). Similarly Astrallet al [9] reported MI in 14\% of their patients and in another study Curie P[10] also reported $14 \%$. During hospitalization $37.5 \%$ (24 out of 64) cases developed LVF, two out of $64(3.1 \%)$ cases developed cardiogenic shock and 3 out of $64(4.7 \%)$ developed CCF and 2 out of $64(3.1 \%)$ cases developed pericaritis. In the present study, 33.3\% (1out of 3) cases who had CCF during hospitalization developed ischemia during Holter monitoring. Mickley [8] found $26 \%$ cases of CCF who developed ischaemia during Holter. Four cases out of $24(16.7 \%)$ who had LVF during hospitalization developed ischemia during Holter monitoring. None of the cases, who had cardiogenic shock or pericarditis during hospitalization developed ischemia during Holter monitoring. Curie P[10] (1993) reported $7 \%$ cases with pericarditis developed ischaemia during holter monitoring. The cause of this inconsistent finding may be difference in number of cases in the studies, difference in the patient group and study design. After acute myocardial infarction, during the period of hospitalization 4 out of $64(6.25 \%)$ cases had VT (sustained), 1 of 64 dissociation and one out of $64(1.6 \%)$ had atrial fibrillation. Mickley(1994)[8] found 13\% cases with VT and $13 \%$ cases of atrial fibrillation developed ischemia during holter monitoring. The difference in finding could be due to small number of patients in the study. The heart rate may vary from marked bradycardia to a rapid regular or irregular tachycardia depending on underlying rhythm and degree of LVF. In the present study 9 out of 64 cases $(14 \%)$ presented with sinus bradycardia as compared to $9 \%$ observed by Meltzer et al (1966).[11] Norris et al (1972)[12] reported similar findings. Ischemia was seen in 3 out of $21(14.28 \%)$ cases of sinus tachycardia as compared to Mickley (1993)[13] who found it in $22 \%$ cases. Two out of $4(50 \%)$ cases of hypotension developed ischemia during holter monitoring while 4 of $50(8 \%)$ normotensive cases developed ischemia. This shows that the patients who present with hypotension at admission have more chances of developing ischemia in post infarction period. One out of $6(16.7 \%)$ cases whose minimum heart rate during holter monitoring was less than $40 \mathrm{bpm}$ recorded ischemia during holter monitoring, while 4 out of 40 (10\%) cases whose heart rate during holter monitoring was between $41-60 \mathrm{bpm}$ developed ischemia. SVPC was the most common arrhythmia recorded in 57 out of 64 (89\%) with equal distribution in anterior wall myocardial infarction, inferior wall myocardial infarction and combined infarction as compared to Cristal et al (1975)[14] who 
recorded them in $36 \%$. Atrial pair was found in $28 \%$ and atrial run in $18.18 \%$, none of the case had atrial flutter or fibrillation. Berisso et al (1990)[15] found SV tachyarrhythmia in $13 \%$ of the cases. After acute myocardial infarction, while predischarge holter monitoring, if patients is put on exertion (noy on TMT) like brisk waking he can achieve heart rate, while is comparable to heart rate achieved during submaximal exercise test. In these cases, who had achieved THR more than or equal to $75 \%$ it can be taken that their submaximal stress testing has been done. In such patients while analyzing holter record, heart rte and ST segment changes could be evaluated.

\section{Conclusion}

After acute myocardial infarction, pre-discharge Holter monitoring (including brisk walk) is a good noninvasive method to detect ischemia in high risk patients who had suffered from sustained ventricular tachycardia, congestive cardiac failure, cardiogenic shock during hospitalization and are not suitable for submaximal exercise stress test. By addition of 100meter brisk walk during holter monitoring, patients who can achieve THR of more than $75 \%$ need not carry out submaximal stress test.

\section{Funding: Nil,Conflict of interest: None. Permission of IRB: Yes}

\section{References}

1. Joseph SA and Garry SF. Cited at Hand book of coronary care. $6^{\text {th }}$ edition, willy publication.2000: 15 107.

2. Bigger JT Jr, Fleiss JL, Kliger R, Miller JP, Rolnitzky LM; Multicenter Post-Infarction Research Group.

\section{Bigger JT Jr, Fleiss JL, Kleiger R, Miller JP, Rolnitzky LM.}

The relationships among ventricular arrhythmias, left ventricular dysfunction, and mortality in the 2 years aftermyocardial infarction. Circulation. 1984 Feb;69(2):250-8.

4.Taylor GJ, Humphries JO, Mellits ED, Pitt B, Schulze RA, Griffith LS, Achuff SC. Predictors of clinical course, coronary anatomy and left ventricular function after recovery from acute myocardial infarction. Circulation. 1980 Nov;62(5):960-70.

5. Risk stratification and survival after myocardial infarction. N Engl J Med. 1983 Aug 11;309(6):331-6.

6. Jereczek M, Andresen D, Schröder J, Völler H, Brüggemann T, Deutschmann $\quad$, Schröder R. Prognostic value of ischemia during Holter monitoring and exercise testing after acute myocardial infarction. Am J Cardiol. 1993 Jul 1;72(1):8-13.

7. Deanfield JE, Maseri A, Selwyn AP, Ribeiro P, Chierchia S, Krikler S, Morgan M. Myocardial ischaemia during daily life in patients with stable angina: its relation to symptoms and heart rate changes. Lancet. 1983 Oct 1;2(8353):753-8.

8. Tzivoni D, Gavish A, Zin D, Gottlieb S, Moriel M, Keren A, Banai S, Stern S. Prognostic significance of ischemic episodes in patients with previous myocardial infarction. Am J Cardiol. 1988 Oct 1;62(10 Pt 1):661-4.

9. Mickley H. Ambulatory ST segment monitoring after myocardial infarction. Br Heart J. 1994 Feb;71(2):1134.

10. Arstall MA, Barromer FA, Horonitz JD. Silent ischemia after uncomplicated myocardial infarction: lack of clinical significance. Int. J. Cardiol 1994; 45. DOI: http://dx.doi.org/10.1016/0167-5273(94)90053-1

11. Currie P, Ashby D, Saltissi S. Prognostic significance of transient myocardial infarction on ambulatory monitoring after acute myocardial infarction. Am. J. Cardiol 1993; 71: 773-777. DOI: http://dx.doi.org/10.1016/0002-9149(93)90822-T

12. Meltzer LE and Kitchell JB. The incidence of arrhythmia associate with acute myocardial infarction. Prog. Cardiovasc. Dis1966; 9(1);50-63.

13. Norris RM, Mercer CJ, Croxson MS. Conduction disturbances due to anteroseptal myocardial infarction and their treatment by endocardial pacing. Am Heart J. 1972 Oct;84(4):560-6.

14. Mickley H, Pless P, Nielsen JR, Berning J, Møller M. Transient myocardial ischemia after a first acute myocardial infarction and its relation to clinical characteristics, predischarge exercise testing and 
cardiac events at one-year follow-up. Am J Cardiol. 1993 Jan 15;71(2):139-44.

15. Cristal N, Peterburg I, Szwarcberg J. Atrial fibrillation developing in the acute phase of myocardial infarction. Prognostic implications. Chest. 1976 Jul;70(1):8-11.
16. Berisso MZ, Carratino L, Ferroni A. Frequency characteristics and significance of supraventricular tachyarrhythmia detected by 24 hour electrocardiographic recording in the late hospital phase of acute myocardial infarction. Am J cardiol 1990; 65: 1064.

\section{How to cite this article?}

Jalali T, Goyal V. A study on survivors of acute myocardial infarction developing transient ischemia on Holter monitoring. Int J Med Res Rev 2015;3(10):1112-1117. doi: 10.17511/ijmrr.2015.110.215. 